\title{
Control of the Charge State of Metal Atoms on Thin MgO Films
}

\author{
Martin Sterrer, ${ }^{1, *}$ Thomas Risse, ${ }^{1}$ Umberto Martinez Pozzoni,${ }^{2}$ Livia Giordano, ${ }^{2}$ Markus Heyde, ${ }^{1}$ Hans-Peter Rust, ${ }^{1}$ \\ Gianfranco Pacchioni, ${ }^{2}$ and Hans-Joachim Freund ${ }^{1}$ \\ ${ }^{1}$ Department of Chemical Physics, Fritz-Haber-Institut der Max-Planck-Gesellschaft, Faradayweg 4-6, D-14195 Berlin, Germany \\ ${ }^{2}$ Dipartimento di Scienza dei Materiali, Universit di Milano-Bicocca, via R. Cozzi 53, I-20125 Milano, Italy
}

(Received 24 November 2006; published 2 March 2007)

\begin{abstract}
The arrangement of single gold and palladium atoms deposited on the surface of a 3 monolayer thin film of $\mathrm{MgO}$ was investigated using low-temperature scanning tunneling microscopy. While Pd atoms are arranged in a random fashion, $\mathrm{Au}$ forms an ordered array on the surface. The long-range ordering as well as the scanning tunneling microscopy appearance of single $\mathrm{Au}$ atoms on a 3 monolayer thin $\mathrm{MgO}$ film can be explained by partial charge transfer from the substrate to Au atoms as predicted recently by density functional theory calculations [Phys. Rev. Lett. 94, 226104 (2005)]. In contrast with that, Au atoms on a thick film were found to be essentially neutral.
\end{abstract}

DOI: 10.1103/PhysRevLett.98.096107

The identification of concepts which allow understanding and subsequently tuning the catalytic properties of heterogeneous catalysts is still one of the key issues of research in catalysis. A variety of different strategies have been put forward over the past decades in the effort to compass and establish a rational design of heterogeneous catalysts [1]. Most of these strategies are based on structure reactivity relationships, taking different aspects of the exceedingly complex systems into account. To this end model systems using metal particles supported on well ordered thin oxide films of appropriate thickness, which allow investigations with the rigor of modern surface science while grasping essential aspects of the complexity of real systems, have proven to give valuable insight into the details of geometric and electronic structure, as well as adsorption and reaction properties [2-6].

It has been recognized that the thickness of the oxide films, as they are grown on metal substrates, may be used as a design principle to create materials of potential in catalysis. A concept to control the catalytic activity of a dispersed metal by the thickness of an insulating oxide layer was introduced some 20 years ago by Cogen et al. using silica layers covering Pt [7]. In this case the catalytic performance for dehydrogenation of cycloalkenes depends significantly on the thickness of the silica films, which was explained by the decreasing transport of hydrogen atoms produced at the $\mathrm{Pt}$ surface through the silica film. The main experimental challenge, however, is to provide undisputable proof for the proposed mechanisms which is usually hampered either by the complexity of the samples investigated and/or the lack of appropriate methodology to exclude interference with alternative mechanisms. Having ultimate control, as available today, over the thickness and structure of the oxide films, these properties may be used to control the charge state and, thus, the catalytic properties of a metal deposited onto them, an idea related to those proposed by Cabrera and Mott in connection with metal oxidation [8].
PACS numbers: 68.43.Fg, 68.37.Ef, 68.47.Gh, 73.61.-r

Early on it was realized that particular sites of a thin oxide film support can provide means to alter the properties of deposited metals. In particular, oxygen vacancies have come under scrutiny since combined experimental and theoretical investigations of $\mathrm{Au}$ clusters on $\mathrm{MgO}$ surfaces point towards the importance of such point defect sites for the catalytic properties of deposited Au clusters due to their ability to donate charge to the metal clusters [9]. It was not until recently that the correlation between presence of color centers and their impact on the properties has been directly verified [10].

However, charging of adsorbed metals must not necessarily involve the presence of defects on the oxide surface: on the basis of density functional theory (DFT) calculations it was proposed that charge transfer may also occur for metal atoms and clusters adsorbed on a supported thin oxide film, provided that the adsorbed metal exhibits a high electron affinity and the film thickness does not exceed a few monolayers (ML) [11-13]. In particular, Au atoms adsorbed on a thin $\mathrm{MgO}$ film grown on $\mathrm{Mo}(001)$ and $\operatorname{Ag}(001)$ are expected to be negatively charged in contrast to their counterparts on bulk $\mathrm{MgO}$ (or thick $\mathrm{MgO}$ films), which were proven to be essentially neutral [14]. Thus, the thickness of the oxide layer may serve as a parameter to tune the electronic properties of supported metals. In the following we apply low-temperature scanning tunneling microscopy (STM) to obtain firm experimental evidence for such a mechanism by comparing the adsorption behavior of single $\mathrm{Au}$ and $\mathrm{Pd}$ atoms on $3 \mathrm{ML}$ thin $\mathrm{MgO}$ films supported on $\operatorname{Ag}(001)$.

Magnesium oxide thin films were prepared by reactive deposition of $\mathrm{Mg}$ in an oxygen ambient using a $\mathrm{Ag}(001)$ substrate. The $\operatorname{Ag}(001)$ single crystal was cleaned by repeated sputter $\left(\mathrm{Ar}^{+}, 10 \mu \mathrm{A} \cdot \mathrm{cm}^{-2}\right) /$ anneal $(700 \mathrm{~K})$ cycles. $\mathrm{Mg}$ was deposited on $\mathrm{Ag}(001)$ from a UHV evaporator at an oxygen pressure of $1 \times 10^{-6} \mathrm{mbar}$ and a substrate temperature of $570 \mathrm{~K}$. The $\mathrm{MgO}$ growth rate was $1 \mathrm{ML} \cdot \mathrm{min}^{-1}$. The experiments were performed in a 
custom-built low-temperature STM operating at $5 \mathrm{~K}$ [15]. $\mathrm{Au}$ and $\mathrm{Pd}$ atoms were evaporated from a hot filament $(T \approx 1000 \mathrm{~K})$ at a deposition rate of $0.1 \mathrm{ML} \cdot \mathrm{min}^{-1}$ and a sample temperature of 5 to $10 \mathrm{~K}$. DFT calculations of the STM images are based on the PW-91 exchange-correlation functional [16] and the VASP program [17,18] (see Ref. [13] for details). $3 \mathrm{ML} \mathrm{MgO}$ have been deposited on four $\mathrm{Ag}$ layers representing the $\operatorname{Ag}(100)$ substrate. Since the $\mathrm{Ag}$ lattice constant $\left(a_{0}=4.16 \AA\right)$ is $2 \%$ smaller than the $\mathrm{MgO}$ one $\left(a_{0}=4.25 \AA\right)$, the $\mathrm{MgO}$ layers are slightly contracted. During geometry optimization, all atoms in the $\mathrm{MgO}$ film and in the two surface nearest $\mathrm{Ag}$ layers were relaxed while the remaining two metal layers were frozen at bulk positions.

Figures 1(a) and 1(b) show STM images $(30 \mathrm{~nm} \times$ $30 \mathrm{~nm}$ ) of $\mathrm{Au}$ and $\mathrm{Pd}$ atoms, respectively, evaporated on a $3 \mathrm{ML}$ thin $\mathrm{MgO}$ film at a substrate temperature of 5$10 \mathrm{~K}$. For the coverage of $\Theta=2-3 \times 10^{-2} \mathrm{ML}$ single metal atoms, imaged as bright protrusions for the given tunneling conditions, are the predominant species on the surface, while aggregates and clusters play only a minor role. The bright squarelike features in the STM images originate from $\mathrm{MgO}$ ad-islands. A qualitative inspection of Fig. 1(a) reveals that $\mathrm{Au}$ atoms are evenly distributed on the surface with rather well defined nearest-neighbor distances, which is an indication for strong adatom interactions. In contrast, Pd atoms [Fig. 1(b)] deposited at the same conditions exhibit a more or less random distribution. Thus, the electronic properties of the adsorbed metal atoms and their interaction with the thin $\mathrm{MgO}$ film play an important role for the observed nucleation behavior. To ensure that the ordering of $\mathrm{Au}$ atoms on thin $\mathrm{MgO}$ films is not mediated by interactions with the metal substrate, such as coupling to surface states or Friedel oscillations [19,20], $\mathrm{Au}$ atoms were also deposited on bare $\operatorname{Ag}(001)$. This situation, shown in Fig. 1(c), reveals a random distribution of $\mathrm{Au}$ atoms indicating that the thin $\mathrm{MgO}$ layer plays an essential role for the observed ordering of $\mathrm{Au}$ atoms on $\mathrm{MgO} / \mathrm{Ag}(001)$.

In an attempt to quantify the adatom interactions, the radial pair distribution function, $f_{\exp }(r)$, was determined from the STM images by counting for each atom the number of neighbors found in a ring of inner diameter $r$ and width $\Delta r$. This radial distribution function is compared to the theoretical expectation for a random occupation of sites, $f_{\text {rand }}(r)$, given by
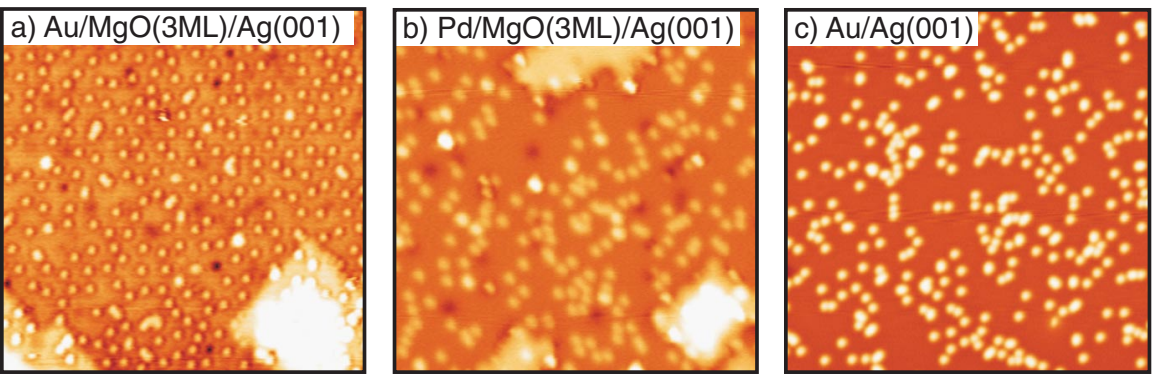

FIG. 1 (color online). STM images $(30 \mathrm{~nm} \times 30 \mathrm{~nm})$ of (a) $\mathrm{Au}$ atoms adsorbed on $3 \mathrm{ML}$ thin $\mathrm{MgO}$ films $(\theta=$ $2.9 \% \mathrm{ML} \mathrm{Au}, V_{S}=+0.5 \mathrm{~V}, I_{T}=11 \mathrm{pA}$ ); (b) $\mathrm{Pd}$ atoms adsorbed on $3 \mathrm{ML}$ thin $\mathrm{MgO}$ films $\left(\theta=2.3 \% \mathrm{ML} \mathrm{Pd}, V_{S}=\right.$ $+0.2 \mathrm{~V}, I_{T}=13 \mathrm{pA}$ ); (c) Au atoms adsorbed on bare $\operatorname{Ag}(001)(\theta=2.9 \% \mathrm{ML}$ $\left.\mathrm{Au}, V_{S}=+0.1 \mathrm{~V}, I_{T}=100 \mathrm{pA}\right)$. 


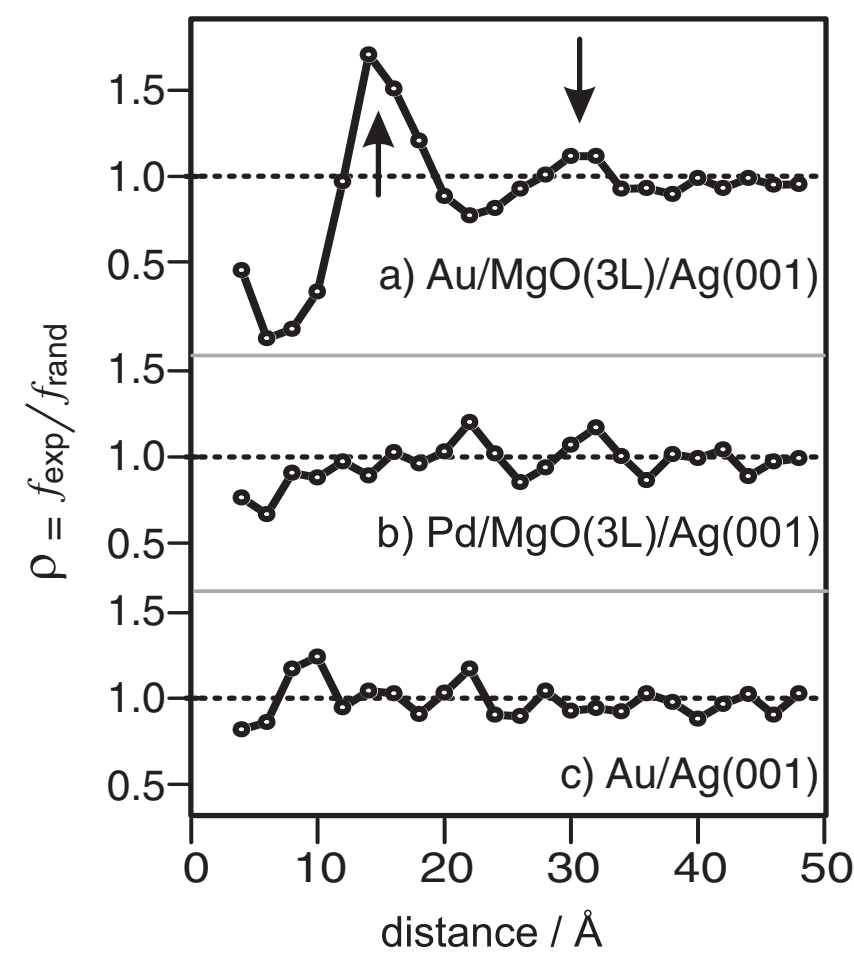

FIG. 2. Normalized radial pair distribution function $\rho=$ $f_{\text {exp }}(r) / f_{\text {rand }}(r)$ for pair distances up to $r=50 \AA$ for (a) $\mathrm{Au}$ atoms adsorbed on $\mathrm{MgO}(3 \mathrm{~L}) / \mathrm{Ag}(001)$, (b) $\mathrm{Pd}$ atoms adsorbed on $\mathrm{MgO}(3 \mathrm{~L}) / \mathrm{Ag}(001)$, and (c) $\mathrm{Au}$ atoms adsorbed on bare $\operatorname{Ag}(001) . \rho=1$ corresponds to random site occupation.

this effect [24]. Two-dimensional ordering was found for $\mathrm{Au}$ atoms on a thin $\mathrm{FeO}(111)$ film on $\mathrm{Pt}(111)$. In this case, the ordering results from an inhomogeneous surface potential induced by a Moiré superlattice [25]. However, neither of the two effects can account for the ordering of $\mathrm{Au}$ atoms on the thin $\mathrm{MgO}$ films.

In a recent theoretical study it has been shown that $\mathrm{Au}$ atoms adsorbed on a thin $\mathrm{MgO}$ film are charged, in contrast to the situation found for unsupported $\mathrm{MgO}$ [11]. This process requires on the one hand a work function reduction of the metal substrate by the thin oxide film, and on the other hand a high electron affinity of the adsorbed metal atoms. For thin $\mathrm{MgO}$ films supported by $\mathrm{Ag}(001)$ or $M o(001)$ a reduction of the work function was found experimentally as well as theoretically [26-29]. In case of $\mathrm{Au}$ atoms adsorbed on supported $\mathrm{MgO}$, DFT calculations reveal a charge transfer towards the $\mathrm{Au}$ atoms for $\mathrm{MgO}$ film thicknesses of 1-5 ML [11,13]. In these calculations the unoccupied part of the Au $6 s$ level shifts below the Fermi energy. The stabilization of this state is strongly driven by the image charge in the Ag substrate and strong structural modifications of the adsorption site on the $\mathrm{MgO}$ surface. With increasing $\mathrm{MgO}$ film thickness these effects diminish in importance and $\mathrm{Au}$ atoms on bulk $\mathrm{MgO}$ or thick films are neutral as shown experimentally for a 20 ML thick film on Mo(100) [14]. As compared to Au, Pd has a much lower electron affinity, thus, DFT calculations show the Pd $5 s$ level to remain above the Fermi energy - meaning the $\mathrm{Pd}$ atoms remain neutral even on ultimately thin $\mathrm{MgO}$ films of $1 \mathrm{ML}$ thickness [11]. Based on these theoretical considerations the experimentally observed two-dimensional order of Au atoms adsorbed on a $3 \mathrm{ML}$ thin MgO film [Fig. 1(a)] can be explained by the repulsive interactions between partially negatively charged $\mathrm{Au}$ atoms. It is important to mention at this point that the adsorbed gold atoms need to diffuse on the surface in order to arrange in the ordered fashion observed. We ascribe this to transient diffusion due to the low diffusion barrier of the charged gold atoms on the surface of the thin $\mathrm{MgO}$ film $\left(E_{d}=0.08 \mathrm{eV}\right.$ [30]) that can be overcome by the energy released during deposition. The $\mathrm{Pd}$ atoms remain neutral when adsorbed on the thin $\mathrm{MgO}$ film and, according to diffusion-limited deposition at the given experimental conditions, are randomly distributed on the surface. This result implies that for Pd adsorption the $3 \mathrm{ML}$ thin $\mathrm{MgO}$ film resembles essentially the properties of bulk $\mathrm{MgO}(100)$, which is consistent with calculated binding energies for $\mathrm{Pd}$ on unsupported and supported $\mathrm{MgO}$ [30], as well as with earlier STM/STS data, which showed that a 3 layer thin $\mathrm{MgO}$ film develops a band gap comparable to the one of bulk $\mathrm{MgO}$ [26].

Is there further evidence that can be acquired from the STM experiments for the interpretation that $\mathrm{Au}$ atoms are charged, whereas $\mathrm{Pd}$ atoms remain neutral when adsorbed on a $3 \mathrm{ML}$ thin $\mathrm{MgO}$ film? To this end we compare the experimental STM signatures of single $\mathrm{Au}$ and Pd atoms with simulated ones applying the Tersoff-Hamann approximation [31] on the electronic structure derived by DFT calculations, where $\mathrm{Au}$ atoms are charged and $\mathrm{Pd}$ atoms are neutral, respectively (Fig. 3). In experiment, the Au atoms are imaged as protrusions surrounded by a depression [Figs. 3(a) and 3(b)], whereas Pd appears as a diffuse protrusion only [Figs. 3(d) and 3(e)]. Both the size of the
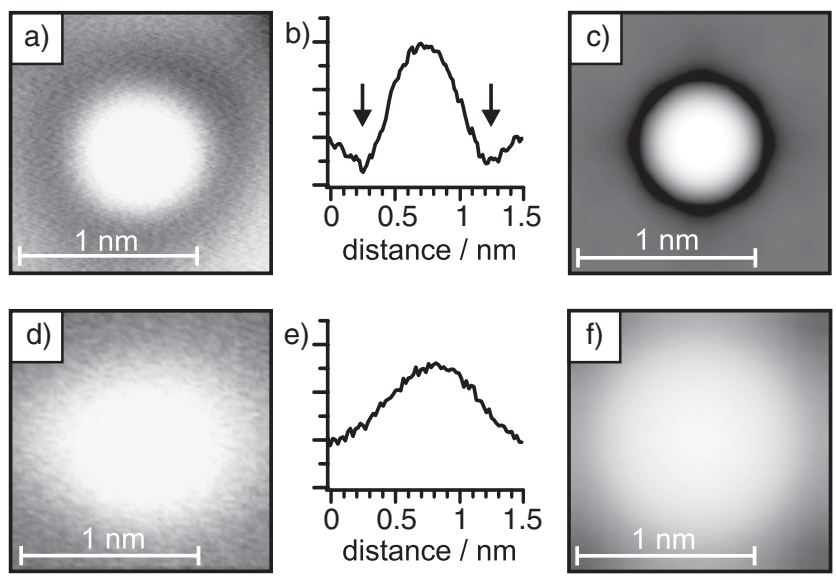

FIG. 3. Experimental STM images and height profiles, and corresponding simulated STM images of single $\mathrm{Au}(\mathrm{a}-\mathrm{c})$ and $\mathrm{Pd}(\mathrm{d}-\mathrm{f})$ atoms on the surface of $3 \mathrm{ML} \mathrm{MgO} / \mathrm{Ag}(001)$, respectively. The bias voltage in the experimental and simulated STM images is $V_{S}=+0.5 \mathrm{~V}$. 
atoms as well as the depression in case of the $\mathrm{Au}$ atom is very well reproduced by the simulated STM images [Figs. 3(c) and 3(f), respectively] corroborating our assignment of the different charge states of the respective metal atoms. This is further shown by the fact that the "sombrerolike" shape in the STM image of the Au atom is not present for a neutral Au adsorbate. Charged gold is stabilized by a strong polaronic distortion of the oxide substrate $[13,30]$, but if the $\mathrm{MgO}$ geometry is fixed to that of truncated bulk the calculation converges to a neutral $\mathrm{Au}^{0}$ adsorbate whose STM image (not shown here for brevity) does not exhibit the depression of Fig. 3(a), and is hardly distinguishable from that of Pd [Fig. 3(d)]. A characteristic depression around $\mathrm{Au}$ atoms was recently observed for $\mathrm{Au}$ on $2 \mathrm{ML}$ thin $\mathrm{NaCl}$ films [32]. However, in the case of $\mathrm{Au} / \mathrm{NaCl}(100) / \mathrm{Cu}(111)$ the atoms were neutral directly after evaporation. Charging of the atoms was induced by a voltage pulse applied between sample and STM tip. In contrast to these experiments the $\mathrm{Au}$ atoms observed on the thin $\mathrm{MgO}$ film show the ringlike depression immediately after deposition indicating that charging of Au occurs in the course of the adsorption process.

It was proposed by theory that similar charging effects as for gold may occur for other adsorbates on thin $\mathrm{MgO}$ films. For example, from DFT calculations a positive charging of potassium atoms when adsorbed on a $2 \mathrm{ML}$ thin $\mathrm{MgO}$ film supported on $\operatorname{Ag}(001)$ was found [13]. Nitrites $\left(\mathrm{NO}_{2}^{-}\right)$are formed due to charge abstraction from the oxide upon adsorption of $\mathrm{NO}_{2}$ on supported $\mathrm{MgO}$ films in contrast to adsorption on unsupported $\mathrm{MgO}$, where $\mathrm{NO}_{2}$ stays essentially neutral [33]. These examples illustrate that the interaction of adsorbates exhibiting particular electronic properties with supported $\mathrm{MgO}$ thin films can give rise to a modification of the properties of adsorbed metals or molecules and can thus be used to tune the chemical activity of these systems.

In conclusion, the results presented in this study provide the first experimental evidence for the presence of charged $\mathrm{Au}$ atoms on a thin, $\mathrm{Ag}(001)$-supported $\mathrm{MgO}$ layer as proposed by calculations [11], in contrast to $\mathrm{Au}$ atoms on thick $\mathrm{MgO}$ films, which were proven to be neutral [14]. No charging effect is evident from our STM data for Pd atoms. As a consequence, while the $\mathrm{Au}$ atoms exhibit twodimensional ordering due to repulsive interactions between the charged entities, no ordering is present for Pd. The observation of the charging of $\mathrm{Au}$ adsorbed on a thin $\mathrm{MgO}$ film is a direct consequence of the work function reduction of the metal substrate by the thin film, and depends critically on the electron affinity of the adsorbed metal. The experimental verification of this hypothesis associates credibility to the proposal to use combinations of various thin oxide films and deposited metals to tune surface reactivity.

The authors are indebted to E.D.L. Rienks for very helpful discussions. This work has been supported by the
European Union through STREP GSOMEN, AURICAT, COST D41, and NoE IDECAT. Further support by the Fonds der Chemische Industrie is acknowledged. G. P. thanks the Alexander von Humboldt foundation for financial support.

*Electronic address: sterrer@fhi-berlin.mpg.de

[1] G. Ertl, H. Knözinger, and J. Weitkamp, Handbook of Heterogeneous Catalysis (Wiley-VCH, Weinheim, 1997).

[2] C. T. Campbell, Surf. Sci. Rep. 27, 1 (1997).

[3] C. R. Henry, Surf. Sci. Rep. 31, 231 (1998).

[4] H. J. Freund, Angew. Chem., Int. Ed. 36, 452 (1997).

[5] H.-J. Freund et al., J. Catal. 216, 223 (2003).

[6] D. W. Goodman, J. Catal. 216, 213 (2003).

[7] J.M. Cogen et al., Angew. Chem., Int. Ed. 26, 1182 (1987).

[8] N. Cabrera and N.F. Mott, Rep. Prog. Phys. 12, 163 (1949).

[9] B. Yoon et al., Science 307, 403 (2005).

[10] M. Sterrer et al., Angew. Chem., Int. Ed. 45, 2630 (2006).

[11] G. Pacchioni, L. Giordano, and M. Baistrocchi, Phys. Rev. Lett. 94, 226104 (2005).

[12] D. Ricci, A. Bongiorno, G. Pacchioni, and U. Landman, Phys. Rev. Lett. 97, 036106 (2006).

[13] L. Giordano and G. Pacchioni, Phys. Chem. Chem. Phys. 8, 3335 (2006).

[14] M. Yulikov et al., Phys. Rev. Lett. 96, 146804 (2006).

[15] M. Heyde et al., Rev. Sci. Instrum. 75, 2446 (2004).

[16] J. P. Perdew et al., Phys. Rev. B 46, 6671 (1992).

[17] G. Kresse and J. Hafner, Phys. Rev. B 47, 558 (1993).

[18] G. Kresse and J. Furthmüller, Phys. Rev. B 54, 11169 (1996).

[19] J. Repp et al., Phys. Rev. Lett. 85, 2981 (2000).

[20] N. Knorr et al., Phys. Rev. B 65, 115420 (2002).

[21] T. T. Tsong, Rep. Prog. Phys. 51, 759 (1988).

[22] R. D. Diehl and R. McGrath, Surf. Sci. Rep. 23, 43 (1996).

[23] J. Trost, T. Zambelli, J. Wintterlin, and G. Ertl, Phys. Rev. B 54, 17850 (1996).

[24] M. Kulawik, N. Nilius, and H.-J. Freund, Phys. Rev. Lett. 96, 036103 (2006).

[25] N. Nilius, E. D. L. Rienks, H.-P. Rust, and H.-J. Freund, Phys. Rev. Lett. 95, 066101 (2005).

[26] S. Schintke et al., Phys. Rev. Lett. 87, 276801 (2001).

[27] L. Giordano, F. Cinquini, and G. Pacchioni, Phys. Rev. B 73, 045414 (2006).

[28] J. Goniakowski and C. Noguera, Interface Sci. 12, 93 (2004).

[29] M. Pivetta, F. Patthey, M. Stengel, A. Baldereschi, and W.-D. Schneider, Phys. Rev. B 72, 115404 (2005).

[30] L. Giordano, M. Baistrocchi, and G. Pacchioni, Phys. Rev. B 72, 115403 (2005).

[31] J. Tersoff and D. R. Hamann, Phys. Rev. B 31, 805 (1985).

[32] J. Repp, G. Meyer, F. E. Olsson, and M. Persson, Science 305, 493 (2004).

[33] H. Grönbeck, J. Phys. Chem. B 110, 11977 (2006). 